\title{
The Mediating Role of Functional Reflection of the Relationship between the Organizational Spectrum and the Morale of Workers
}

\author{
*Ahmed Ghazi Mahdi, ** Raeda Malallah Mohammed \\ *Iraqi Ministry of Health \\ **Department of Office Managemant \\ Institute of Administrtionrusafa \\ Middle Technical University
}

DOI: 10.37648 /ijrssh.v10i03.039

Received: 20 July, 2020; Accepted: 25th August, 2020; Published: 02 ${ }^{\text {nd }}$ September,2020

\begin{abstract}
The purpose of the current research is to know the interactive role of career meditation in the relationship between the organizational spectrum and the behavior of green workers represented in (business sustainability, avoiding harm, conservation, and influencing others, and taking initiatives), and the research relied on the questionnaire as a key tool to collect the necessary and necessary data to achieve its goal. As (265) forms were distributed to determine the level of availability of international human resources management and job alienation, (245) forms were retrieved, in addition to that a set of statistical methods was used, represented by weighted mean, standard deviation, Spearman simple correlation coefficient, and simple and multiple regression coefficient. The results of the research showed a positive correlation with statistically significant relationship between international human resources management and the functional alienation of the sample, and the research showed a direct impact relationship between the organizational spectrum, green worker behavior and job meditation of the sample. The research came out with a set of recommendations, the most important of which is that there is a clear emphasis by the respondent sample on providing opportunities to develop the skills of individuals through the provision of training, educational and development programs for them
\end{abstract}

\section{INTRODUCTION}

In view of the development, complexity and rapid changes in the business environment and its departure from the local borders to the global borders of the world, which were characterized by increased interference and international and economic relations and the difference in the nature of the performance of the jobs and tasks required and the diversity of skills and expertise needed to perform the business, which led to adding tasks to the organizational spectrum in the organization in order to manage this world the new. Hence the job of green workers behavior is one of the important jobs in creating value and preserving it in business organizations, as the job meditation process is one of the important aspects that addresses the problems and issues experienced by workers when performing their work, and from here this research came to highlight the ways and methods that It can be followed to address green worker behavior.

The research has been divided into four sections, the first topic resulted in the research methodology and the problem and its importance and objectives and hypotheses, while the second topic included the theoretical aspect of the research, and the third topic was 
(IJRSSH) 2020, Vol. No. 10, Issue No. III, Jul-Sep

based on the reality of the applied side of the research, while the fourth topic dealt with the conclusions and recommendations that the research reached.

\section{RESEARCH METHODOLOGY}

\section{First: the research problem}

The rapid environmental developments and the big leaps in the business world contributed to the business organizations supporting and enhancing their environmental aspects through their functional contemplation, which is the basis for every organization that seeks to preserve the environment, which we must use a certain type of organizational spectrum, which is the basis that focuses on it The organization promotes the diversity of groups and the strengthening of individuals working in the workplace by diverting attention away from the principles and strategies of affirmative action (Slack, 1997: 75), and from this standpoint the following question arises (what is the best functional meditation method through which using the conservative organizational spectrum On the regulatory environment). Thus, the research problem can be explained in the following points- :

1-What is the level of the organizational spectrum of the sample?

2-How can the green workers behavior of the sample be addressed?

3-What is the level of job integration that the sample possesses?

4-Is there a correlation between the organizational spectrum, green worker behavior, and job meditation?

5-Is there any direct or indirect impact of the organizational spectrum on the behavior of green workers through the interactive role of career meditation?

\section{Second: The importance of research}

The importance of the research stems from the fact that it will measure the correlation and influence relations between the research variables, as well as the existence of

\section{e-ISSN: 2249-4642, p-ISSN: 2454-4671}

another importance that can be explained in the following points- :

1-There are no foreign or Arab researches that combine functional contemplation, organizational spectrum, and green worker behavior

2-There are no Arab papers that have examined the issue of the regulatory spectrum

3-This study contributed to the definition of the research sample on the topic of functional meditation, organizational spectrum, and green worker behavior.

\section{Third: - Research objectives}

The goals that the research seeks to answer can be determined:

1-Determining the level of job integration that the respondent owns.

2-Determine the extent of the contribution to job integration by using the organizational spectrum to address the behavior of green workers to protect the environment

3- Knowing whether there is a correlation, direct or indirect effect between the research variables.

\section{Fourth: The hypothetical research scheme}

In light of what was discussed in the study methodology and objectives, the hypothetical study plan was prepared, see Figure (1), to express the relationship between the study variables, and this chart is represented by a set of correlations and effects between the study variables and the following:

1-The independent variable: It represents the organizational spectrum, and it is a one-dimensional variable.

2-The dependent variable: - The behavior of green workers in its dimensions (sustaining work, avoiding harm, preserving, influencing others, and taking initiatives.(

3- The interactive variable: - It results in functional integration, which is a one-dimensional variable 


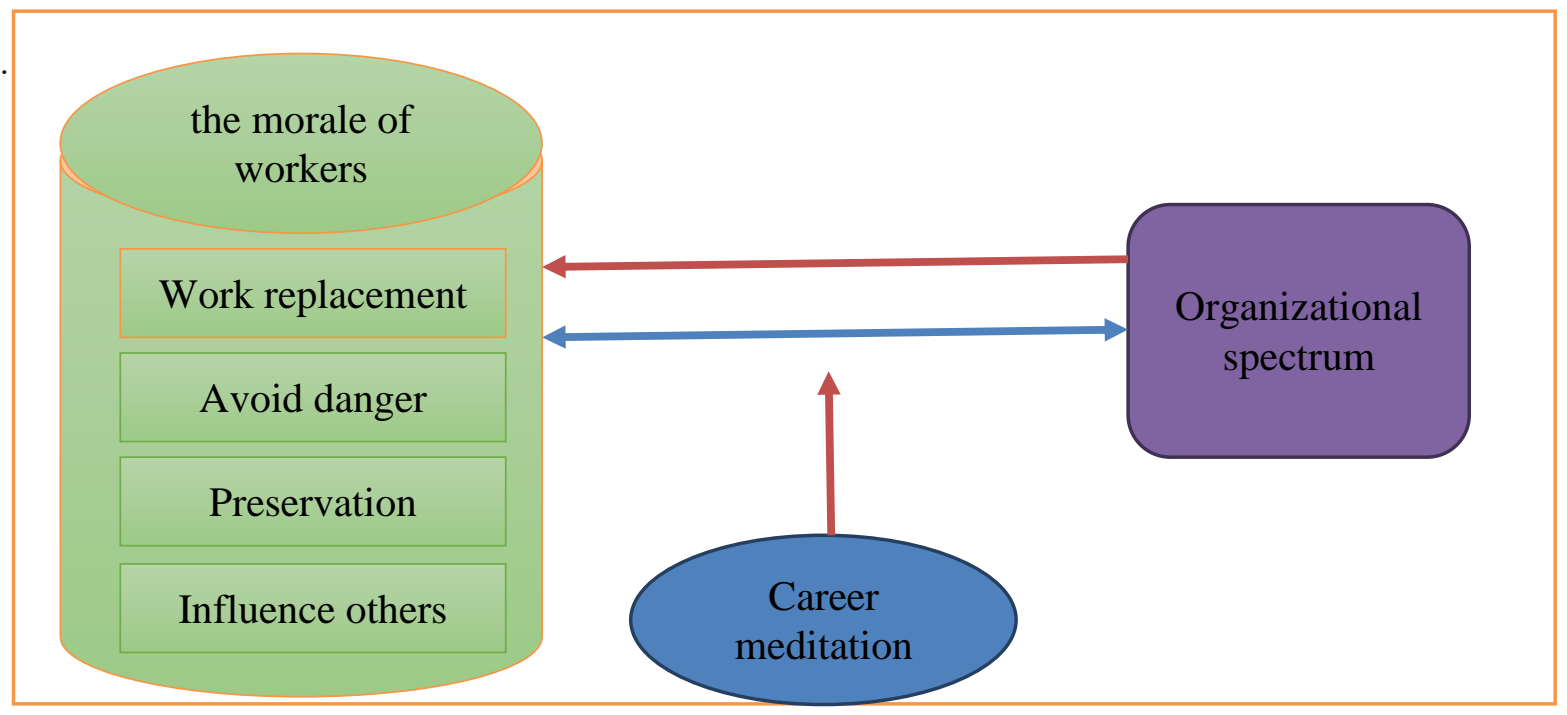

Figure (1) research hypothesis

Fifth: research hypotheses correlation hypotheses

1-There is a statistically significant correlation between the organizational spectrum and functional integration 2-There is a statistically significant correlation between the organizational spectrum and green workers behavior with its dimensions

3-There is a statistically significant correlation between functional meditation and the behavior of green workers in its dimensions

Impact hypotheses

Direct hypotheses

1-There is a direct statistically significant effect of the organizational spectrum on functional integration.

2-There is a direct, statistically significant effect of the organizational spectrum on the behavior of green workers and its dimensions (work sustainability, avoidance of harm, conservation, influence on others, and taking initiatives)

\section{Indirect hypotheses}

There is a statistically significant interactive effect of the organizational spectrum on the behavior of green workers and its dimensions (work sustainability, avoiding damage, conservation, influencing others, and taking initiatives) through functional meditation as an interactive role between the two variables

\section{THE SECOND TOPIC: - THEORETICAL FRAMEWORK FOR THE RESEARCH}

\section{First: Functional Meditation}

1-The concept of functional meditation

Meditation involves maintaining practices that emphasize an increased focus on the desired attention group. Meditation (Luu, 2016) can involve either focusing on a more specific group ("focusing attention on meditation") such as intention (for example, gratitude) or an object A diamond (for example, a candle flame), or a wider group, which corresponds to the current state of the kiss (Luu, 2016: 1). While (Cahn \&Polich, 2006) believes that the term meditation is used to describe practices that regulate self and body, which affects mental events through the participation of groups of workers in specific attention. These practices are a subset of those used to induce relaxation or change events such as hypnosis, progressive relaxation, and techniques to induce extra effort. (Vaitl et al., 2005: 98) Given that task organization is a common feature of many different methods, meditative patterns 
can usefully be categorized into two types of meditation and focus - (Andresen, 2000: 17) depending on how attention is directed. Most meditation techniques are located somewhere on a continuum between these two attributes - mind and focus (Cahn \&Polich, 2006: 180). (Froeliger et al., 2012) concluded that practicing meditation is a means of achieving psychological consensus and self-awareness (Chiesa \&Serretti, 2009: 593), but it has only recently become the target of systematic research by fields such as medicine, psychology, and neuroscience as it relates to mental And physical health. Meditation is increasingly seen on the curative promise of these sciences (Ludwig \&KabatZinn, 2008: 1350), and according to recent concepts, the practice of functional meditation (involves a recurring mode of attention to a particular thing through the recognition of alternation and the exit from the dispersion of thoughts and emotions), Career meditation works over and over time (Gaylord et al., 2011: 1678), and it may build up in a trait (Teasdale et al., 2000: 275.). The state of functional meditation is characterized by (perception of the moment when a certain event occurred, emotion, perception, and sensation) (Froeliger et al., 2012: 1.(

Lazar et al. (2005) believes that career meditation is a form of mental practice that has become a popular health practice in the United States (Genovese et al., 2002: 870). It is reported that the systematic practice of career meditation to bring about changes in the psychological state reflects well on the working individuals by providing physical comfort and promoting health activity for them (Wallace et al., 1971: 795), so the practice of regular functional meditation should also lead to major changes In infrastructure in organizations that routinely participate during this mental process (Lehrer et al., 1999: 812). Formal practice involves the constant concern of internal and external sensory stimuli (Lazar et al., 2005: 1895). (Jayadevappa et al., 2007: 75) promoted that meditation is a simple mental technique capable of practicing any working individual, whether in family life or in the work life, which lasts (15-20) minutes twice daily (Hulsmann et al., 2002). : 886). (Taylor et al., 2012: 1) emphasized that functional meditation is useful for treating mental disorders that involve emotional disorders, such as major depressive disorder, anxiety disorders, and alertness that encourage an objective way of interpreting thoughts, events and emotions. (Wong et al., 2015: 98) claimed that functional meditation is open, unconscious or observational awareness of ongoing cognitive processing of ideas at the present time constant attention.

\section{2-The importance of career meditation}

-Reducing stress and improving clinical outcomes across various issues such as depression (Froeliger et al., 2012: 1; Jayadevappa et al., 2007: 74.

-Providing psychological and physiological well-being for working individuals (Luders et al., 2009: 672.(

-Promoting emotional stability (Taylor et al., 2012: 1.)

-Achieving the complementarity and interdependence between the body and mind of working individuals (Tang et al., 2010: 15649).

-5Reorganization of knowledge resources (Xue et al., 2011: 570).

3- Features and characteristics of career meditation

-The state of functional meditation: - refers to sensory, cognitive, and self-awareness changes that can arise through the practice of functional meditation (Vaitl et al., 2005: $98 .($

- The feature of career meditation: - Refers to the permanent changes in these dimensions that are still in career meditation regardless of participation in a specific activity in career meditation (Cahn \&Polich, 2006: 181)

\section{Second: - Organizational spectrum}

The organizational spectrum is one of the main pillars on which the organization focuses on enhancing the diversity of groups and strengthening individuals working in the workplace (Chambers, T. \&Riccucci, 1997: 8) by diverting attention away from the principles and strategies of affirmative action (Slack, 1997: 75). Transformations are a process in which the organization solves the problems it faces by directing its environment, internal resources, and its position to solve these problems (Resca et al, 2013: 72), and organizations face intense competition for survival, which should focus on technology, products, and new markets. In order to achieve this goal (transformation) (Stockport, 2000: 45). Transformation is the best strategy companies use to be competitive. On the other hand, some researchers consider that transformation is an art, whereby the working individuals do better over time (Cheng et al, 2009: 145), so that most companies have to learn, develop and hone their skills in order to acquire four skills. The basis of it is (Kim, 1998: 506) (subconscious inefficiency, conscious inefficiency, conscious efficacy, 
and unconscious competence (Jayashree\& Yang, 2015: 134)

\section{2-Organizational spectrum tasks}

Emphasis is placed on ensuring comprehensive or complete diversity in the workplace, which motivates workers to achieve diversity in the organizational spectrum by shaping strategies to be applied in the workplace (Chambers, T. \&Riccucci, 1997: 8) that aim to - :

1-Eliminate perceived or actual weaknesses that currently exist in many affirmative action practices.

2- Maintaining the strengthening of the various assets in the organizational workplace (Slack, 1997: 75).

\section{3-Dynamic access to the regulatory spectrum}

This paragraph reflects the current policy direction for fixed regulatory spectrum management, as broad indications include a different approach to regulatory spectrum reform. These dynamics can be limited to the following- :

\section{1-The exclusive dynamics used in the model}

This model maintains the basic structure of the current policy of regulatory spectrum regulation: the regulatory spectrum bands authorize services for exclusive use (Coase: 1959: 1). The main idea is to introduce flexibility to improve the efficiency of the regulatory spectrum. Two approaches have been proposed under this model: regulatory spectral property rights and dynamic spectrum allocation (Hatfield \& P. Weiser, 2005: 6). The previous entry allows the licensees to freely sell the regulatory spectrum and choose the technology. Consequently, the economy and the market will play a more important role in driving towards the more profitable use of this limited resource (Xu et al., 2000: 281). Also, although licensees have the right to rent or participate in the regulatory spectrum for profit, this sharing is not mandated by the regulation policy (Zhao \& Sadler, 2006: 2).

This paragraph aims to improve the efficiency of the regulatory spectrum by allocating a dynamic regulatory spectrum that exploits the spatial and temporal movement statistics for the various services. In addition to allocating the organizational spectrum in a specific organization and at a specific time (Xu et al., 2000: 282). However, this allocation differs on a much faster scale than in the current policy. Based on the exclusive use model, this entry cannot eliminate white space in the regulatory spectrum resulting from the successive nature of the wireless traffic (Zhao \& Sadler, 2006: 3.(

\section{2-Free participation form}

This model is also referred to as the organizational spectral commons, and is used as an open sharing between peer users as the basis for management of an organizational spectrum area (Lehr \& J. Crowcroft, 2005: 5). Advocates of this model attract support from the tremendous success of wireless services operating in the unlicensed band (Raman et al., 2005: 110), as (leri et al., 2005: 3) regulatory spectrum allocation strategies were initially investigated and allocated to address Technological challenges within this regulatory spectrum management model (Zhao \& Sadler, 2006: 3).

\section{3-Hierarchical Access Form}

This paragraph is built on a hierarchical access structure with primary and secondary users, and this model can be considered as a combination of the first and second dynamics (Mitola, 1999: 3). The basic idea is to open the regulatory spectrum licensed to secondary users and reduce the interference perceived by the main (authorized) users (Mitola, 2000,6). Two approaches were considered to share the organizational spectrum between primary and secondary users: the basis of the regulatory spectrum and the regulatory spectrum overlay (Zhao \& Sadler, 2006: 3).

\section{Third: - the morale of workers}

1-The concept of the morale of workers

The environment is the primary element of the existence of business organizations in the twenty-first century, as the issue of green worker behavior is the subject of the hour being a specific place of rational behavior, (Ones \&Dilchert, 2012: 85). Green worker behavior is any individual measurable behavior that contributes to minimizing the effects Environmental in the context of organizational work (Norton et al., 2015: 103). Moreover, Norton classified the behavior of green workers into five important categories (Starik\& Marcus, 2000: 539), in order to maintain environmental

To be environmentally sustainable, we need to reinforce employee behaviors, influence and change them in line with the goals of sustainable environmental organizations (Anderson, \& White, 2011: 55). Green worker behavior is a set of scalable procedures and behaviors in which employees are integrated in contributing to, or 
contributing to, environmental sustainability (Wiernik et al., 2016: 2). These behaviors can be implemented as a condition of employment or optional organizational citizenship behaviors. Sometimes, these behaviors can be counterproductive because they actually detract from the organization's environmental performance (Ones \&Dilchert, 2012: 87), rather than reinforcing it. As "scalable" measures, they can vary in terms of how frequently employees perform or perform efficiently, and this scalability permits the amount of each employee's contribution (McConnaughy, 2014: 1)

\section{2-Theories of the morale of workers}

There are four theories that explain and characterize the behavior of green workers (Ramus \&Killmer, 2007: 555; Stern, 2000: 410; Norton et al., 2015: 105; Young et al, 2013: 701), which can be summarized as follows- :

\section{1-Situational theory (attitudes)}

This theory is based on the fact that individuals working are influenced by attitudes and activities that are compatible with their internal situations, positions are necessary but not sufficient (Starik\& Marcus, 2000: 539), as it requires individuals to possess beliefs surrounding them in order to control their behavior and be on Evidence of social standards in order to perform the required behavior of them. The planned behavior theory is one of the most prominent frameworks for explaining environmental behavior in both the private sector (Bamberg \&Möser, 2007: 17) and work (Unsworth et al, 2013: 214), and attitudes may also act as coordinator of the relationships between green worker behavior and factors. At other levels (Bissing-Olson et al., 2013: 158). As attitudes affecting the environment have a positive impact on the behavior of green workers, as there is a stronger relationship between the positive effect and the behavior of green workers for individuals who have more negative environmental attitudes (Norton et al., 2015: 105).

\section{2-Standard theory (standards)}

This theory focuses on the extent to which behavior is socially acceptable, as this theory suggests that the rules guide behavior by emphasizing the social consequences of participation or lack of it in certain activities (Ones \&Dilchert, 2012: 85), and environmental sustainability research has focused on this theory Mostly green behavior in the private sphere (Norton et al., 2014: 52). 3-Mutual theory (exchange)
This theory focused on the role of interactions, especially reciprocity, between the individual and some other entities such as leaders or groups (Cropanzano\& Mitchell, 2005: 875). Within this perspective, behavior is assumed to be driven by obligations arising from reciprocal relationships such as the relationship between leaders and subordinates, and that these obligations are in turn driven by "exchange rules (Cropanzano\& Mitchell, 2005: 875), which include reciprocity (recovery), and negotiated outcomes ( Surrender), altruism, and group goals. Social exchange theory has recently been applied to explain the nature of environmental citizenship behavior (Paillé\&Boiral, 2013: 121; Paillé, Boiral, \& Chen, 2013: 3554; Paillé et al., 2016: 657). On this, (Temminck et al., 2015: 403) used this perspective to assume that reciprocity between employees and the organization might mediate the effect of environmental attitudes on the behavior of environmental citizenship.

\section{4-Motivational theory (motivation)}

This theory refers to factors that motivate a specific decision to enter into a behavior, as well as the intensity and perseverance of the effort. For example, in the theory of self-determination (Deci \& Ryan, 1985) they assume that behavior is the result of independent and controlled incentives. Thus the employee's incentive is to enter into green behavior in order to do this (the self-motivation), or if they think the organization will put a reward to them (motivating them to move forward). (Graves et al., 2013: 83 ) used the theory of self-determination to clarify the behavior of green workers as they include independent incentives such as attitudes and values, as well as those controlled by them such as EMS and rewards. In short, the literature seems to have adopted a wide range of theoretical perspectives to clarify the behavior of green workers.

\section{Fourth: the dimensions of behavior green workers}

Business Sustainability: It is the processes that help work and product sustainability at the highest level. This dimension refers to the following behaviors:

-Choosing responsible alternatives: are the behaviors in which the employee chooses the option of work or process that is more environmentally friendly

Changing how you do business: are the behaviors through which business processes are changed to become more sustainable ((Ones \&Dilchert, 2012: 87( 
Creating sustainable products and processes: These are the behaviors in which new products or processes are created that are more environmentally friendly

Embracing Innovation for Sustainability: are the behaviors in which new, more sustainable technology is adopted at work (McConnaughy, 2014: 70(

Avoiding harm: - Behaviors that cause harm to the environment. This dimension refers to the following behaviors:

Pollution / Pollution Prevention: behaviors that cause or prevent pollution ((Ones \&Dilchert, 2012: 87((

Environmental Impact Monitoring: are the behaviors in which work activities are monitored to assess and understand how they affect the environment

Ecosystem strengthening: behaviors that help protect or repair ecosystems from the effects of industry and business (McConnaughy, 2014: 70(

Preservation: These are the behaviors that aim to help conserve resources and reduce damage. This dimension refers to the following behaviors:

Reduced use: Behaviors that prevent unnecessary use of new substances

Reuse: These are behaviors where the materials are used multiple times for the same purpose ((Ones \&Dilchert, 2012: 87((

Recycle: are the behaviors where materials are used multiple times for new purposes

Recycling: is the behavior in which materials are recycled (ending in a recycling center) (McConnaughy, 2014: 70)
4-Influencing others: - are the social behaviors used to influence others in order to integrate into environmental behaviors. This dimension refers to the following behaviors: - (Ones \&Dilchert, 2012: 87)

Encourage and support others: Behaviors that promote and encourage green behaviors are another employee Education and Training for Sustainability: Behaviors that help others build their knowledge about the environment (McConnaughy, 2014: 71)

\section{THE THIRD TOPIC: - THE PRACTICAL SIDE}

\section{First: - Analysis of the normal distribution}

Before each calculation of the statistical data drawn from a randomly selected sample, we must subject this data to a set of special tests to see whether it is possible to generalize the results drawn to society, and therefore we have to take advantage of the Kolmogorov - Smirnov test and Shapiro - Wilk in order to find out whether these data can be generalized or not, if the moral value of them is greater than (0.05) which is an acceptable value and is acceptable. Consequently, it can be said that the results of these tests pave the way for the use of statistical statistical tools for the purpose of testing the validity of the hypotheses developed and verifying the reliability and reliability of the measurement tools used in the research.

Table (3) tests the normal distribution of data withdrawn according to the Klomgrove-Simneroff test, Shapiro-Willeck for the functional meditation variable

\begin{tabular}{|l|l|l|l|l|l|l|}
\hline \multicolumn{6}{|l|}{ Tests of Normality } \\
\hline \multirow{2}{*}{} & \multicolumn{2}{|l|}{ Kolmogorov-Smirnov $^{\mathrm{a}}$} & \multicolumn{3}{l|}{ Shapiro-Wilk } \\
\cline { 2 - 7 } & Statistic & $\mathrm{df}$ & Sig. & Statistic & df & Sig. \\
\hline FM & .118 & 345 & .000 & .946 & 345 & .000 \\
\hline OS & .117 & 345 & .000 & .942 & 345 & .000 \\
\hline SS & .092 & 345 & .000 & .965 & 345 & .000 \\
\hline RR & .132 & 345 & .000 & .954 & 345 & .000 \\
\hline TT & .059 & 345 & .005 & .981 & 345 & .000 \\
\hline EE & .173 & 345 & .000 & .940 & 345 & .000 \\
\hline NN & .105 & 345 & .000 & .974 & 345 & .000 \\
\hline EGB & .050 & 345 & .000 & .985 & 345 & .000 \\
\hline
\end{tabular}


(IJRSSH) 2020, Vol. No. 10, Issue No. III, Jul-Sep

We note from the results in the above table that the moral value of the normal distribution test is higher than (0.05), which means that the data follow the normal distribution, which can be relied upon that we can use laboratory tests.

\section{Second: - Confirmatory factor analysis}

For the purpose of verifying the structural validity of the research tool, we have to perform a confirmatory factor analysis test on the study variables, as empirical factor analysis is used, which is one of the applications of structural modeling equation in the process of identifying and testing the built models and the extent of their validity and suitability for the study under study as it includes latent variable variables that The assumed dimensions, the measured internal variables or the
e-ISSN: 2249-4642, p-ISSN: 2454-4671

endogenous that represent the paragraphs (questions). These expressions are related to the dimensions through shares that go from the underlying variables to the internal variables.

\section{1-Career meditation variable}

We learn from this paragraph the structural structure of the functional integration variable through an analysis of the global structural affirmation of the functional integration paragraphs, and the lower figure shows the structural structure of this variable, while the results presented in Table (4), it represents the standard ramifications of the functional integration paragraphs and the extent of the participation of these paragraphs in the interpretation of this variable.

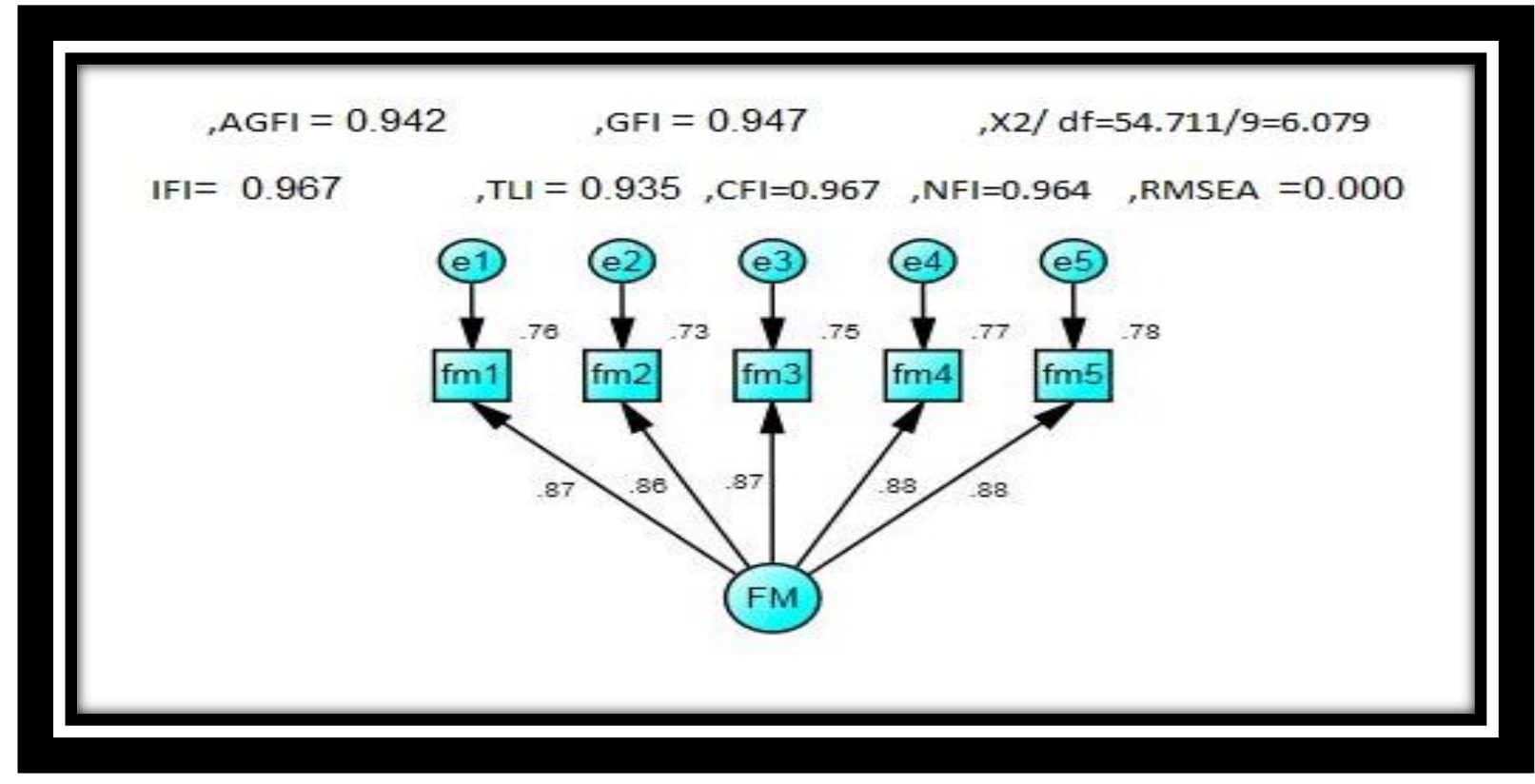

Figure (2) the structural diagram of the functional meditation paragraphs

Table (4): Standard Replications of Paragraphs of Functional Meditation

\begin{tabular}{|l|l|l|l|}
\hline \multicolumn{2}{|l|}{ Item } & Estimate \\
\hline fm1 & $<---$ & FM & .874 \\
\hline fm2 & $<---$ & FM & .856 \\
\hline fm3 & $<---$ & FM & .865 \\
\hline fm4 & $<---$ & FM & .878 \\
\hline fm5 & $<---$ & FM & .883 \\
\hline
\end{tabular}




\section{2-The organizational spectrum variable}

This paragraph shows the extent of the use of the (AMOS version (23) program in the analysis of the global structural affirmative diagram of the organizational spectrum items.

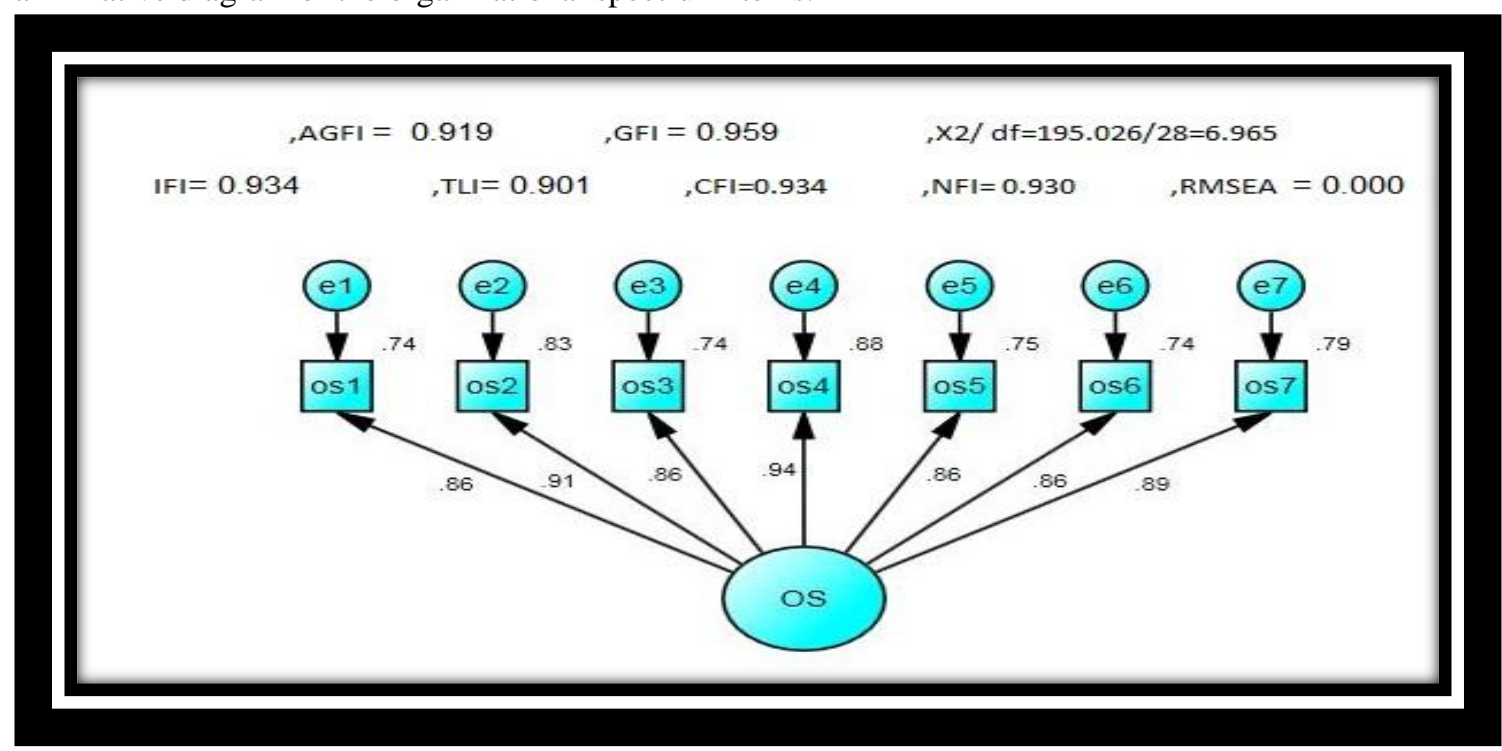

Figure (3) the structural diagram of the regulatory spectrum

Table (5) normative saturation and explanatory values of the organizational spectrum variable

\begin{tabular}{|l|l|l|l|}
\hline \multicolumn{2}{|l|}{ Item } & Estimate \\
\hline os1 & $<---$ & OS & .859 \\
\hline os2 & $<---$ & OS & .910 \\
\hline os3 & $<---$ & OS & .862 \\
\hline os4 & $<---$ & OS & .936 \\
\hline os5 & $<---$ & OS & .864 \\
\hline os6 & $<---$ & OS & .860 \\
\hline os7 & $<---$ & OS & .891 \\
\hline
\end{tabular}

\section{3-Green worker behavior variable}

We note from the results presented in Figure (4), which shows the structural structure of the paragraphs of green worker behavior, while Table (6) shows the norms and weights of the norms of the variable of green worker behavior. 


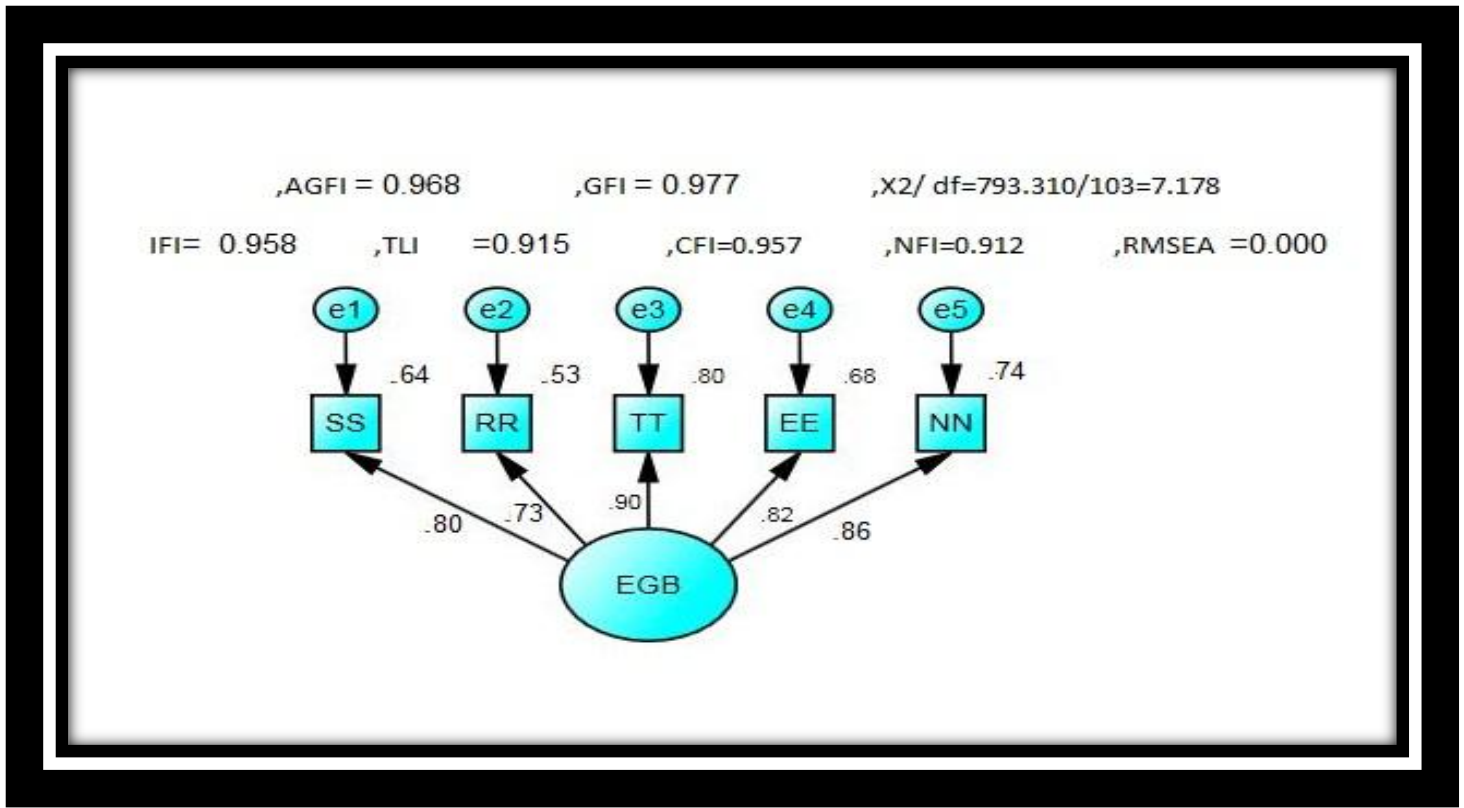

Figure (4) the structural diagram to exclude the behavior of green workers

Table (6) norms and weights for the green workers behavior variable

\section{Fourth: The correlation and influence between research variables}

\begin{tabular}{|l|l|l|l|}
\hline \multicolumn{2}{|l|}{ Item } & Estimate \\
\hline SS & $<---$ & EGB & .800 \\
\hline RR & $<---$ & EGB & .731 \\
\hline TT & $<---$ & EGB & .896 \\
\hline EE & $<---$ & EGB & .825 \\
\hline NN & $<---$ & EGB & .864 \\
\hline
\end{tabular}

1-correlation between search variables

This paragraph is concerned with clarifying whether there is a correlation between variables and dimensions of research on the one hand, and testing hypotheses on the other hand by using the simple correlation coefficient

Table (15) Correlations between the organizational spectrum, green workers behavior, its dimensions, and functional meditation (345) $\mathrm{N}$

\begin{tabular}{|c|c|c|c|c|c|c|c|c|}
\hline $\begin{array}{l}\text { Pearson } \\
\text { Correlation }\end{array}$ & OS & SS & RR & $\mathrm{TT}$ & $\mathrm{EE}$ & $\mathrm{NN}$ & EGB & $\begin{array}{l}\text { OS } \\
* \text { FM }\end{array}$ \\
\hline OS & 1 & & & & & & & \\
\hline FM & $.923^{* *}$ & & & & & & & \\
\hline SS & $.856^{* *}$ & 1 & & & & & & \\
\hline RR & $.956^{* *}$ & $.849^{* *}$ & 1 & & & & & \\
\hline TT & $.712^{* *}$ & $.702^{* *}$ & $.755^{* *}$ & 1 & & & & \\
\hline $\mathrm{EE}$ & $.187^{* *}$ & $.267^{* *}$ & $.217^{\text {** }}$ & $.734^{* *}$ & 1 & & & \\
\hline $\mathrm{NN}$ & $.642^{* *}$ & $.714^{* *}$ & $.676^{* *}$ & $.931^{* *}$ & $.809^{* *}$ & 1 & & \\
\hline EGB & $.764^{* *}$ & $.807^{* *}$ & $.799^{* *}$ & $.965^{* *}$ & $.734^{* *}$ & $.971^{* *}$ & 1 & \\
\hline OS*FM & $.968^{* *}$ & $.882^{* *}$ & $.963^{* *}$ & $.764^{* *}$ & $.258^{* *}$ & $.697^{* *}$ & $.815^{* *}$ & 1 \\
\hline
\end{tabular}




\section{The effect relationship between the search variables}

This paragraph explains the relationship of influence between research variables, as it takes into account two important points:

1-The effect of the organizational spectrum on the behavior of green workers and its dimensions.

2-The effect of the organizational spectrum on the behavior of other workers through the interactive role of career meditation

First: - The effect of the organizational spectrum on the behavior of green workers and its dimensions.

We note from the results presented in Figure (5) that there is an effect relationship between the research variables, and this is what the main hypothesis stipulates, which states that "(there is an effect of the organizational spectrum on the behavior of green workers)" and this effect reached (0.76). The thing that can be relied upon is that this hypothesis is correct and therefore we accept the hypothesis

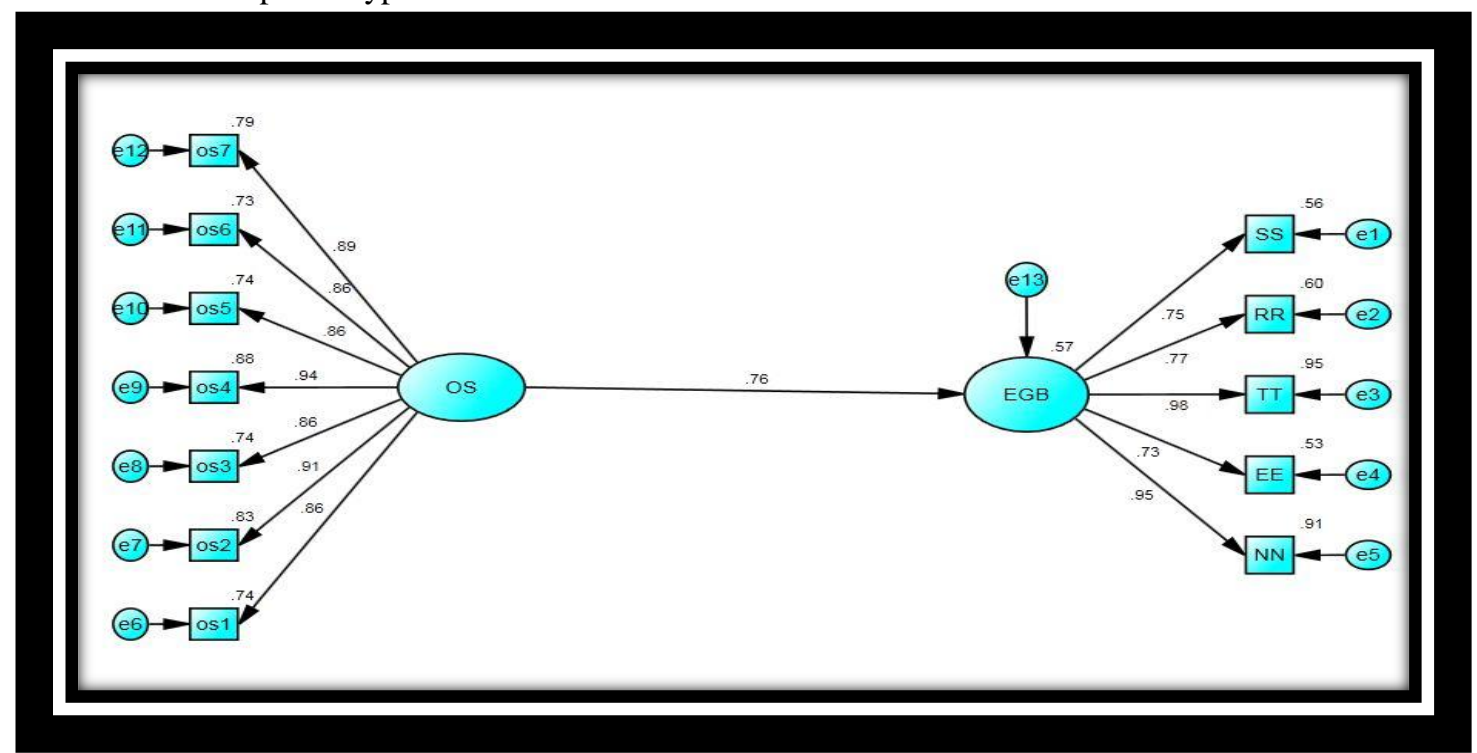

Figure (5) effect relationship between search variables

Second: - The effect of the organizational spectrum on green workers' behavior through the interactive role of career meditation.

This paragraph explains the effect of the organizational spectrum on green worker dielectrics by removing it through the interactive role of functional meditation. As the new interactive variable was extracted by striking the organizational spectrum in functional meditation and the new mathematical outcome is the result of the interaction between them. It is clear from the figure below that the acceptance of the influence hypothesis states that ("There is an effect of the organizational spectrum by interacting with functional meditation on the green worker behavior represented by work sustainability (SS)) (0.99). 


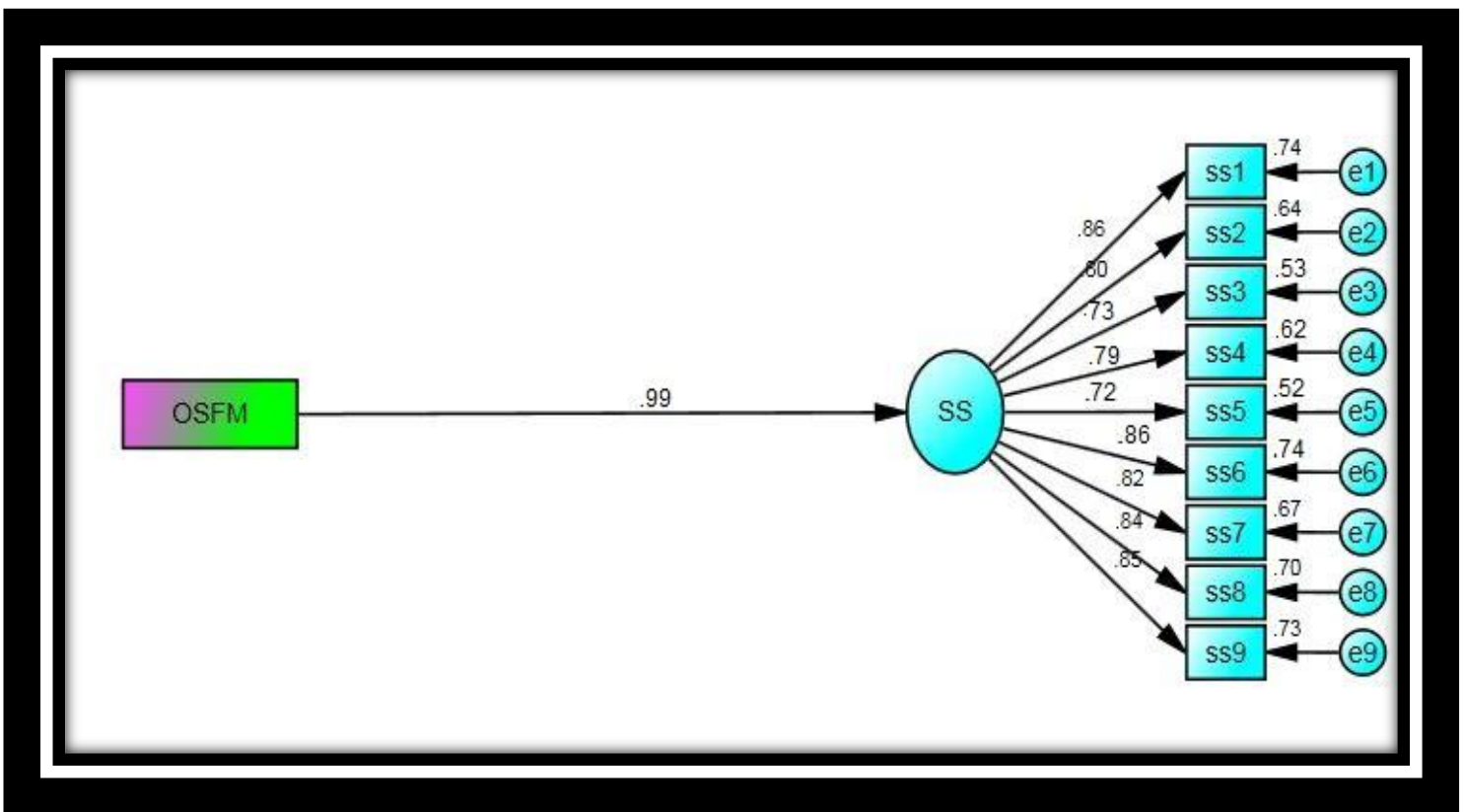

Figure (6): The relationship of the effect of the organizational spectrum with the interaction with functional meditation on the green worker behavior represented by work sustainability

We note from the results presented in Figure (7) that there is an effect of the organizational spectrum by interacting with functional meditation on the green worker behavior of avoiding damage (RR) has reached (0.99)

\section{THE FOURTH TOPIC: - CONCLUSIONS AND RECOMMENDATIONS}

\section{1-Conclusions}

-The statistical analysis demonstrated the existence of a strong correlation and impact relationship between the organizational spectrum, green worker behavior (work sustainability, avoiding damage, conservation, influencing others, and taking initiatives), and career integration. Which means that the respondent must emphasize the need to maintain effective performance.

-There is a clear interest from the researched sample on developing relations with its employees and various stakeholders in order to achieve its goals and the goals of its employees.

-There is a clear emphasis by the respondent sample on providing opportunities to develop the skills of individuals through providing training, educational and development programs for them.

-The research sample is keen to provide specialists in the field of information technology, especially in the field of preserving the regulatory environment in order to avoid making common mistakes that the organizations fall into.

-The sample is keen on developing the necessary goals and measures in order to maintain its level.

\section{Second: - Recommendations}

-The need for the respondent sample to enhance the ability of its employees to participate in training courses, conferences and discussions in order to enhance the ability of workers in the organization to complete employment.

-The need for the respondent to emphasize possessing the appropriate talents and expertise in order to support her superior performance.

-The need for the respondent sample to support and strengthen health programs in order to achieve a balance between work and the individual life of the individual.

-The need for the sample to provide a database in order to facilitate internal operations and facilitate the process of completing tasks easily and conveniently. 
(IJRSSH) 2020, Vol. No. 10, Issue No. III, Jul-Sep

-It is imperative that the sample respondent to develop different performance evaluation indicators for the different actions and their units.
e-ISSN: 2249-4642, p-ISSN: 2454-4671

-The need for the research sample to focus on providing the necessary means for the well-being of its employees and developing different services for them that are in line with their needs in order to preserve them

\section{SOURCES AND REFERENCES}

1) McConnaughy, J. C. (2014). "DEVELOPMENT OF AN EMPLOYEE GREEN BEHAVIOR DESCRIPTIVE NORMS SCALE." California State University - San Bernardino, Electronic Theses, Projects, and Dissertations, PP 1- 105

2) Wiernik, B. M., Dilchert, S., \& Ones, D. S. (2016). Age and employee green behaviors: A meta-analysis. Frontiers in psychology, 7.pp 1-15

3) Tariq, S., Jan, F. A., \& Ahmad, M. S. (2016). Green employee empowerment: a systematic literature review on state-of-art in green human resource management. Quality \& Quantity, 50(1), pp237-269.

4) Graves, L. M., Sarkis, J., \& Zhu, Q. (2013). How transformational leadership and employee motivation combine to predict employee proenvironmental behaviors in China. Journal of Environmental Psychology, 35, pp81-91.

5) Deci, E. L., \& Ryan, R. M. (1985). Intrinsic motivation and self-determination in human behavior. New York, NY: Plenum.

6) Cropanzano, R., \& Mitchell, M. S. (2005). Social exchange theory: An interdisciplinary review. Journal of Management, 31, pp 874-900.

7) Paillé, P., \&Boiral, O. (2013). Pro-environmental behavior at work: Construct validity and determinants. Journal of Environmental Psychology, 36, pp118-128

8) Paillé, P., Boiral, O., \& Chen, Y. (2013). Linking environmental management

9) practices and organizational citizenship behavior for the environment: A social exchange perspective. International Journal of Human Resource Management, 24, pp 3552-3575.

10) Paillé, P., Mejía-Morelos, J. H., Marché-Paillé, A., Chen, C. C., \& Chen, Y. (2016). Corporate greening, exchange process among co-workers, and ethics of care: An empirical study on the determinants of pro-environmental behaviors at coworkers-level. Journal of Business Ethics, 136(3), pp655-673.

11) Temminck, E., Mearns, K., \&Fruhen, L. (2015). Motivating employees towards sustainable behaviour. Business Strategy and the Environment, 24(6), pp402-412.

12) Norton, T. A., Zacher, H., \&Ashkanasy, N. M. (2014). Organisational sustainability policies and employee green behavior: The mediating role of work climate perceptions. Journal of Environmental Psychology, 38,pp 49-54.

13) Ramus, C. A., \&Killmer, A. B. C. (2007). Corporate greening through prosocial extrarole behaviors: A conceptual framework for employee motivation. Business Strategy and the Environment, 16, pp554-570.

14) Stern, P. C. (2000). Toward a coherent theory of environmentally significant behavior. Journal of Social Issues, 56, pp407424.

15) Young, W., Davis, M., McNeill, I. M., Malhotra, B., Russell, S., Unsworth, K., \& Clegg, C. W. (2013). Changing behavior: Successful environmental programmes in the workplace. Business Strategy and the Environment. 24,pp 689703

16) Bissing-Olson, M., Iyer, A., Fielding, S., \&Zacher, H. (2013). Relationships between daily affect and pro-environmental behavior at work: The moderating role of pro-environmental attitude. Journal of Organizational Behavior, 34, pp156-175.

17) Norton, T. A., Parker, S. L., Zacher, H., \&Ashkanasy, N. M. (2015). Employee green behavior: A theoretical framework, multilevel review, and future research agenda. Organization \& Environment, 28(1), pp103-125.

18) Norton, T. A., Zacher, H., \&Ashkanasy, N. M. (2015). Pro-environmental organizational culture and climate. In J. L. Robertson \& J. Barling (Eds.), The psychology of green organizations (pp. 322-348). New York, NY: Oxford University Press. 
19) Bamberg, S., \&Möser, G. (2007). Twenty years after Hines, Hungerford, and Tomera: A new meta-analysis of psychosocial determinants of pro-environmental behavior. Journal of Environmental Psychology, 27, pp14-25.

20) Unsworth, K. L., Dmitrieva, A., \&Adriasola, E. (2013). Changing behavior: Increasing the effectiveness of workplace interventions in creating pro-environmental behavior change. Journal of Organizational Behavior, 34,pp 211-229

21) Xue, S., Tang, Y. Y., \& Posner, M. I. (2011). Short-term meditation increases network efficiency of the anterior cingulate cortex. Neuroreport, 22(12), 570-574.

22) Tang, Y. Y., Lu, Q., Geng, X., Stein, E. A., Yang, Y., \& Posner, M. I. (2010). Short-term meditation induces white matter changes in the anterior cingulate. Proceedings of the National Academy of Sciences, 107(35), pp 15649-15652

23) Taylor, V. A., Daneault, V., Grant, J., Scavone, G., Breton, E., Roffe-Vidal, S., ...\& Beauregard, M. (2012). Impact of meditation training on the default mode network during a restful state. Social cognitive and affective neuroscience, $8(1)$,pp 4-14.

24) Luders, E., Toga, A. W., Lepore, N., \&Gaser, C. (2009). The underlying anatomical correlates of long-term meditation: larger hippocampal and frontal volumes of gray matter. Neuroimage, 45(3), pp 672-678.

25) Lazar, S. W., Kerr, C. E., Wasserman, R. H., Gray, J. R., Greve, D. N., Treadway, M. T., ... \& Rauch, S. L. (2005). Meditation experience is associated with increased cortical thickness. Neuroreport, 16(17), pp 1893.-1897

26) Froeliger, B., Garland, E. L., Kozink, R. V., Modlin, L. A., Chen, N. K., McClernon, F. J., ... \&Sobin, P. (2012). Meditation-state functional connectivity ( $\mathrm{msFC}$ ): strengthening of the dorsal attention network and beyond. EvidenceBased Complementary and Alternative Medicine, PP 1 -9.

27) Cahn, B. R., \&Polich, J. (2006). Meditation states and traits: EEG, ERP, and neuroimaging studies. Psychological bulletin, Vol. 132, No. 2, PP 180.-211

28) Luu.K,2016" Comparing the Acute Effects of Hatha Yoga and Meditation on Executive Function" A thesis presented to the University of Waterloo in fulfillment of the thesis requirements for the degree of Master of Science in Health Studies and Gerontology

29) Jayadevappa, R., Johnson, J. C., Bloom, B. S., Nidich, S., Desai, S., Chhatre, S., ...\& Schneider, R. H. (2007). Effectiveness of transcendental meditation on functional capacity and quality of life of African Americans with congestive heart failure: a randomized control study. Ethnicity \& disease, 17(1),pp 72-77.

30) Wong, W. P., Camfield, D. A., Woods, W., Sarris, J., \&Pipingas, A. (2015). Spectral power and functional connectivity changes during mindfulness meditation with eyes open: A magnetoencephalography (MEG) study in long-term meditators. International Journal of Psychophysiology, 98(1), pp 95-111.

31) Zhao,Q\&Sadler,B,2006 "Dynamic Spectrum Access: Signal Processing, Networking, and Regulatory Policy" SUBMITTED TO IEEE SIGNAL PROCESSING MAGAZINE, SEPTEMBER, PP 1- 20

32) Sreenivasan Jayashree.S\&Yang.X,2015 "Firm's typology and strategic innovation among Chinese cosmetic industry - a strategic transformation tool" Int. J. Technology Management, Vol. 67, Nos. 2/3/4, PP 132-147

33) Slack, J. D. (1997). From affirmative action to full spectrum diversity in the american workplace: Shifting the organizational paradigm. Review of Public Personnel Administration, 17(4), pp 75-87.

34) William Acar Kenneth E. Aupperle Ronald M. Lowy, (2001),"AN EMPIRICAL EXPLORATION OF MEASURES OF SOCIAL RESPONSIBILITY ACROSS THE SPECTRUM OF ORGANIZATIONAL TYPES", The International Journal of Organizational Analysis, Vol. 9 Iss 1 pp. $26-57$.

35) Resca.A,Za.S\&Spagnoletti.P,2013 "Digital Platforms as Sources for Organizational and Strategic Transformation: A Case Study of the Midblue Project" Journal of Theoretical and Applied Electronic Commerce Research, VOL 8, Pp 71-84

36) Park, Hun Myoung, (2008), "Univariate Analysis and Normality Test Using SAS, Stata, and SPSS", Working Paper, The University Information Technology Services (UITS) Center for Statistical and Mathematical Computing, Indiana University.

37) Brown, James Dean, (1997), "Skewness and kurtosis", JALT Testing \& Evaluation SIG Newsletter, Vol. 1, No.(1), pp:2023. 
38) Hair, J.F., Black, W.C., Babin, B.J., \& Anderson, R.E. (2010). "Multivariate Data Analysis" ,7 ${ }^{\text {th }}$ ed., Prentice Hall, Upper Saddle. , Chan, F., Lee, G., Lee, E., Kubota, C., \& Allen, Ch., (2007), "Structural Equation Modeling in Rehabilitation Counseling Research", Rehabilitation Counseling Bulletin, 51:1, 53-66.

39) Nunnaly, J.C. \& Bernstein, I.H., (1994)," Psychometric theory", New York: McGraw-Hill.

40) Vaitl, D., Birbaumer, N., Gruzelier, J., Jamieson, G. A., Kotchoubey, B., Kubler, A., et al. (2005). Psychobiology of altered states of consciousness. Psychological Bulletin, 131, 98-127.

41) Andresen, J. (2000). Meditation meets behavioural medicine: The story of experimental research on meditation. Journal of Consciousness Studies, 7, 17-73.

42) Chiesa\&Serretti,2009 "Mindfulness-based stress reduction for stress management in healthy people: a review and metaanalysis," Journal of Alternative and Complementary Medicine, vol. 15, no. 5, pp. 593-600.

43) Ludwig\&Kabat-Zinn,2008 "Mindfulness in medicine," Journal of the American Medical Association, vol. 300, no. 11, pp. $1350-1352$,

44) Teasdale, R. G.Moore, H. Hayhurst,M.Pope, S.Williams, and Z. V. Segal,2002 "Metacognitive awareness and prevention of relapse in depression: empirical evidence," Journal of Consulting and Clinical Psychology, vol. 70, no. 2, pp. 275-287,

45) Gaylord, O. S. Palsson, E. L. Garland et al., 2011"Mindfulness training reduces the severity of irritable bowel syndrome in women: results of a randomized controlled trial," American Journal of Gastroenterology, vol. 106, no. 9, pp. 1678-1688,.

46) Genovese CR, Lazar NA, Nichols TE ,2002. Thresholding of statistical maps in functional neuroimaging using the false discovery rate. Neuroimage ; 15:870-878.

47) Wallace RK, Benson H, Wilson AF, 1971. A wakeful hypometabolic physiological state. Am J Physiol ;221:795-799.

48) Lehrer P, Sasaki Y, Sauti Y, 1999. Zazen and cardiac variability. PsychosomMed ;61:812-821.

49) Hulsmann M, Berger R, Sturm B, et al ,2002. Prediction of outcome by neurohormonal activation, the sixminute test and the Minnesota Living with Heart Failure Questionnaire in an outpatient cohort with congestive heart failure. Eur Heart J ;23(11):886-891

50) Coase, 1959“The federal communications commission,” J. Law and Economics, pp. 1-40, .

51) D. Hatfield and P. Weiser,2005 "Property rights in spectrum: taking the next step," in Proc. of the first IEEE Symposium on New Frontiers in Dynamic Spectrum Access Networks,.

52) Xu, R. Tonjes, T. Paila, W. Hansmann, M. Frank, and M. Albrecht,2000 "DRiVE-ing to the Internet: Dynamic Radio for IP services in Vehicular Environments," in Proc. of 25th Annual IEEE Conference on Local Computer Networks, pp. 281 -289 ,

53) Lehr \&J. Crowcroft,2005 "Managing shared access to a spectrum commons," in Proc. of the first IEEE Symposium on New Frontiers in Dynamic Spectrum Access Networks.

54) Raman, R. Yates, and N. Mandayam,2005 "Scheduling Variable Rate Links via a Spectrum Server," in Proceedings of the first IEEE Symposium on New Frontiers in Dynamic Spectrum Access Networks, pp. 110-118, .

55) Ileri, D. Samardzija, and N. Mandayam,2005 "Demand Responsive Pricing and Competitive Spectrum Allocation via a Spectrum Server," in Proceedings of the first IEEE Symposium on New Frontiers in Dynamic Spectrum Access Networks,

56) , "Cognitive radio for flexible mobile multimedia communications," in Proc. IEEE International Workshop on Mobile Multimedia Communications, pp. 3-10, 1999.

57) Mitola,2000, Software Radios: Wireless Architecture for the 21 st Century. John Wiley \& Sons Inc, .

58) Chambers, T. \&Riccucci, N. M. (1997). Models of excellence in workplace diversity. In C. Ban and N. M. Riccucci (Eds.), Public

59) Stockport, G.J. (2000) 'Developing skills in strategic transformation', European Journal of Innovation Management, Vol. 3, No. 1, pp.45-52.

60) Cheng, B-W., Bor-Wen Luo, C-M., Chiu, W-H. and Chen, K-H. (2009) 'Applying cluster analysis to build a patientcentric healthcare service strategy for elderly patients', Int. J. of Technology Management, Vol. 47, Nos. 1/2/3, pp.145160.

61) Kim, L. (1998) 'Crisis construction and organizational learning: capability building in catching-up at Hyundai Motor', Organizational Science, Vol. 9, No. 4, pp.506-521 
62) Starik, M., \& Marcus, A. A. (2000). Introduction to the special research forum on the management of organizations in the natural environment: A field emerging from multiple paths, with many challenges ahead. Academy of Management Journal, 43, 539-546.

63) Ones, D. S., \&Dilchert, S. (2012a). Employee green behaviors. In S. E. Jackson, D. S. Ones, \& S. Dilchert (Eds.), Managing human resources for environmental sustainability (pp. 85-116). San Francisco, CA: Jossey-Bass

64) Ones, D. S., \&Dilchert, S. (2012b). Environmental sustainability at work: A call to action. Industrial and Organizational Psychology: Perspectives on Science and Practice, 5, 444-466. 